\title{
Descentralização, participação e controle externo sobre os governos municipais no Brasil
}

\author{
Angela Moulin S. Penalva Santos \\ angelapenalva@terra.com.br
}

\section{Resumo:}

O artigo investiga a suposta existência de relação entre descentralização e maior controle social a que se submetem os governos municipais com base num estudo sobre o controle social e aquele que resulta da ação do Ministério Público em municípios de médio porte localizados no Estado do Rio de Janeiro, Brasil. Estes controles foram criados e/ou fortalecidos após a redemocratização do país e havia a expectativa de que seriam importantes agentes de maior participação da sociedade sobre uma estrutura de poder mais fragmentada depois que os municípios tornaramse "entes federativos". O resultado aponta para um baixo controle por parte dos conselhos municipais, mas uma ação importante por parte do Ministério Público, ainda que muito mais significativa no que tange às políticas ambientais do que ao ordenamento urbanístico ou às políticas descentralizadas de saúde e educação.

Palavras-chave: descentralização, município, políticas públicas, controle externo

\section{Resumen}

El artículo investiga la supuesta existencia de la relación entre la descentralización y un mayor control social a los cuales se someten los gobiernos municipales basados en un estudio sobre el control social y uno que siga la acción del Ministerio Público en los municipios de tamaño mediano situados en el Estado de Rio de Janeiro, Brasil. Estos controles fueron creados y/o consolidados después de la redemocratización del país y había la expectativa que los agentes serían 
importantes para una mayor participación en la sociedad en una estructura de poder más fragmentada después de la conversión de los municipios en "entidades federativas". El resultado indica un bajo control de los consejos municipales, pero una acción importante del Ministerio Público, aún más significativa en términos de políticas ambientales que el planeamiento o las políticas de salud y de educación descentralizadas.

Palabras-clave: descentralización, municipalidad, políticas públicas, control externo

\begin{abstract}
The paper investigates the alleged existence of the relationship between decentralization and greater social control to which municipal governments are submitted based on a study on the social control and one that follows the action of the Prosecutors in medium-sized municipalities located in the State of Rio de Janeiro, Brazil. These controls were created and/or strengthened after the redemocratization of the country and there was an expectation that they would be important agents for greater participation in society on a more fragmented structure of power after the municipalities have become "federal entities". The result indicates low municipal councils' control, but important public prosecutors' action, even more significant in terms of environmental policies than with regards to urban planning or decentralized health and education policies.
\end{abstract}

Keywords: decentralization, municipality, public policies, external control

Palabras-chave: descentralización, municipalidad, políticas públicas, control externo

\title{
1 - Introdução
}

O objetivo deste estudo é avaliar a relação entre descentralização e controle externo exercido sobre as prefeituras de sete municípios fluminenses, selecionados por ISSN 1981-9021 - Geo UERJ - Ano 11, v.2, n.19, $1^{\circ}$ semestre de 2009. P. 17-43 www.geouerj.uerj.br/ojs 
sua condição de cidade média e por se localizarem em diferentes regiões do estado, levando-as a experimentar desafios de distintas naturezas. Na pesquisa que originou este estudo, foram considerados os controles exercidos pelo Ministério Público, através das promotorias de tutela coletiva e o controle social, mediante análise do funcionamento dos conselhos municipais de Saúde, Educação e de Política Urbana. Neste artigo, será dado destaque ao controle institucional sob a responsabilidade do Ministério Público.

Além desta primeira seção introdutória, o artigo apresenta outras quatro. $\mathrm{Na}$ segunda, o objetivo é associar descentralização das políticas públicas ao controle externo, considerado premissa para o sucesso das políticas sob responsabilidade dos governos locais. Na terceira, traça-se um breve perfil dos municípios selecionados para a pesquisa de campo, justificando a escolha feita. A quarta seção trata da análise da referida pesquisa, dividida em duas subseções: a primeira dedicada aos principais resultados do controle social, enquanto que a segunda analisa o papel do Ministério Público e suas ações no período de 2000 a 2005. Na quinta e última seção são apresentados os principais resultados da pesquisa.

\section{2 - Descentralização e controle externo}

A centralização do poder pelos Estados Nacionais foi colocada em xeque desde o início da década de 1980. Segundo RESTREPO e CARDENAS (2004), esses Estados submetem-se a uma tripla tensão: "para dentro, mediante processos de descentralização; para fora, pelo aprofundamento da globalização econômica; e, em terceiro lugar, em direção ao mercado mediante privatização dos ativos estatais". Neste artigo, vamos explorar aspectos do primeiro tipo de tensão mencionado: a descentralização das políticas públicas em direção aos entes governamentais infranacionais. 
O argumento mais freqüentemente utilizado em favor da descentralização baseia-se na premissa da melhora do gerenciamento do setor público, já que o governo local tem maior capacidade de alocar eficazmente os bens públicos cujos benefícios sejam espacialmente localizados. Outro argumento importante é que o fornecimento de bens públicos pelos governos locais proporciona maior flexibilidade e melhor adaptação dos investimentos públicos às preferências da população. Ademais, o fato de o governo municipal atuar sobre um universo menor de cidadãos favorece a maior participação popular na formulação das políticas, o que democratiza as estruturas de poder e territorializa a demanda por cidadania, de "baixo para cima", conferindo legitimidade ao poder público. Portanto, ao partir da singularidade do local, a defesa das políticas de descentralização parece confirmar que as políticas macroeconômicas globalizantes convivem com particularismos das políticas locais.

A descentralização é um processo político que envolve o fortalecimento institucional e financeiro dos governos locais. Logo, não deve ser confundida com a mera desconcentração administrativa.

Duas idéias são centrais para compreender o objetivo e a efetividade do processo de descentralização: a de autonomia e a de participação. A primeira avançou significativamente no caso da Federação brasileira: desde 1988, entrou em vigor a atual Constituição, que tornou o município um ente federativo, contando com autonomia administrativa, política, legislativa e financeira. Diferentemente de outras estruturas federativas, na brasileira o município deixou de estar tutelado pelos governos estaduais, o que aumenta muito seu papel na estrutura de poder, ainda que se possa discutir a extensão pretendida e a realmente experimentada da autonomia financeira municipal ${ }^{1}$.

A participação, por sua vez, pode resultar do comportamento cívico dos residentes de uma comunidade, como bem demonstrou PUTNAM (1996) a propósito da experiência da região central da Itália ${ }^{2}$. Entretanto, tal comportamento cívico é fruto da

\footnotetext{
${ }^{1}$ A propósito da distância entre o desenho institucional e a realidade em relação à autonomia financeira dos municípios, consultar SANTOS (2006a).

2 Também chamada "Terceira Itália", para diferenciar os padrões distintos de desenvolvimento que vigoram na industrializada região norte do país e na pobre e não-industrializada região sul.

ISSN 1981-9021 - Geo UERJ - Ano 11, v.2, n.19, $1^{\circ}$ semestre de 2009. P. 17-43

www.geouerj.uerj.br/ojs
} 
tradição milenar de cooperativismo desenvolvido pela cultura local, o que gerou uma forma de organização territorial e de governo mais democrática, "de baixo para cima". Não é o caso das cidades selecionadas neste estudo, algumas das quais criadas em torno de um empreendimento industrial - como Volta Redonda, que se desenvolveu em torno da Companhia Siderúrgica Nacional, inaugurada em 1946.

A teoria institucionalista, no entanto, considera que a participação pode ser engendrada "de cima para baixo", por meio de reformas na estrutura de governo. Aderindo às idéias de NORTH (1990), o Banco Mundial passou a estimular reformas de Estado (WDR, 1997 e 2002) em cujo âmbito a descentralização se destaca como uma das principais propostas, justamente em função da melhora da gestão pública submetida a maior controle social.

O institucionalismo revê a estilização do comportamento humano (seja ele econômico ou político), tomado apenas como maximizador do auto-interesse. Em vez disso, olha a ação dos indivíduos ampliada pela lente de outras dimensões societárias, associadas às normas institucionais, aos valores culturais e à história dos países.

Em contexto de crescente globalização dos mercados e retração do Estado Nacional como sujeito das políticas de desenvolvimento, o novo paradigma tornou mais crucial o papel dos processos de accountability, de responsabilização do gestor público numa estrutura democrática e descentralizada de governo.

A responsabilização democrática inclui: i) o processo eleitoral, garantidor da soberania popular; ii) o controle institucional durante os mandatos, que fornece os mecanismos de fiscalização contínua dos representantes eleitos e da alta burocracia com responsabilidade decisória; e iii) a criação de regras estatais intertemporais, através das quais o poder governamental é limitado em seu escopo de atuação, visando à garantia dos direitos dos indivíduos e da coletividade que não podem ser alterados pelo governo de ocasião (ABRUCIO e LOUREIRO, 2004).

No Brasil, o processo de descentralização veio acompanhado de reformas constitucionais que ampliaram o alcance desses controles sobre o poder público. Neste estudo, será dado destaque ao controle dos governos durante o mandato dos prefeitos. A análise será feita para que se avalie se está correta a hipótese dos defensores do ISSN 1981-9021 - Geo UERJ - Ano 11, v.2, n.19, $1^{\circ}$ semestre de 2009. P. 17-43 www.geouerj.uerj.br/ojs 
paradigma institucionalista em um contexto de descentralização das estruturas de poder.

\section{3 - Pesquisa de campo: breve perfil dos municípios selecionados}

Após duas décadas em que a descentralização passou a ser tratada como uma das principais estratégias de reforma do Estado, o que se verifica em vários países da América Latina ${ }^{3}$ é que tem havido mais desconcentração do que descentralização nas estruturas de poder (RESTREPO, 2006). A razão disso seria a grande desigualdade prevalecente nesses países, que experimentaram crescimento econômico e modernização institucional tendo o governo central como sujeito do processo, num período de meio século - aproximadamente entre 1930 e 1980.

As enormes disparidades interpessoais e inter-regionais levaram parcelas minoritárias da população a serem beneficiárias daquilo que foi chamado "modernização conservadora", fazendo-as experimentar os avanços nos direitos de cidadania. A grande maioria da população dos países latino-americanos, contudo, vive em "estado de necessidade", conforme a sagaz observação do historiador brasileiro José Murilo de Carvalho ${ }^{4}$, o que a torna dependente das políticas assistencialistas do Estado. Para ela, o fortalecimento institucional dos governos locais não resulta em benefícios potenciais como aqueles que podem experimentar os residentes nas áreas mais ricas destes países.

Os residentes nas regiões Sudeste e Sul do Brasil são aqueles que mais podem se beneficiar da descentralização, uma vez que vivem numa área que produz aproximadamente $75 \%$ do PIB do País. E mais, podem se beneficiar da descentralização aqueles que vivem nas cidades de médio e grande porte, onde a

\footnotetext{
${ }^{3}$ Casos do Brasil, da Argentina, da Colômbia e do México, como se pode verificar em SANTOS e UGÁ (2007).

${ }^{4}$ Em diversas entrevistas à imprensa escrita e à televisão, a propósito da capacidade de atuação do Estado Nacional brasileiro ao longo do ano de 2007.

ISSN 1981-9021 - Geo UERJ - Ano 11, v.2, n.19, $1^{\circ}$ semestre de 2009. P. 17-43

www.geouerj.uerj.br/ojs
} 
concentração do PIB e da renda é elevada, o que lhes permite suportar maior carga fiscal (SANTOS, 2006b).

As sete cidades selecionadas neste estudo localizam-se no Estado do Rio de Janeiro, estado responsável pelo segundo maior PIB estadual, avaliado em aproximadamente $12 \%$ do PIB do País (2005). Trata-se de uma participação muito menor do que a do Estado de São Paulo, cujo PIB é de cerca de $33 \%$ do brasileiro ${ }^{5}$. Os dois estados, no entanto, são vizinhos e formam uma região economicamente dinâmica e onde se localizam as duas metrópoles nacionais: os municípios de Rio de Janeiro e de São Paulo.

Dentre as cidades selecionadas, seis estão localizadas no interior do Estado do Rio, e apenas uma situa-se na Região Metropolitana do Rio de Janeiro. Apesar de importantes diferenças socioeconômicas entre elas, todas constituem importantes elos da rede urbana fluminense, cumprindo papel relevante na estruturação do território estadual (e até nacional, em alguns casos).

A tabela a seguir resume os principais indicadores socioeconômicos para que seja possível traçar um breve perfil de cada uma dessas cidades.

Tabela 1: Perfil dos municípios selecionados, a partir de alguns indicadores socioeconômicos

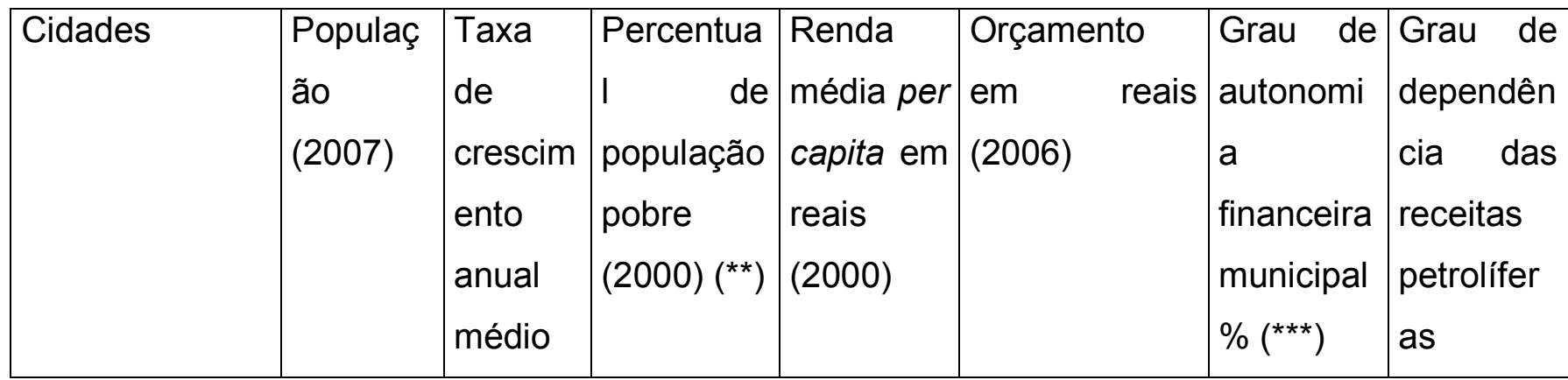

\footnotetext{
${ }^{5}$ O Estado de São Paulo foi o principal beneficiário do processo de desenvolvimento pela via da industrialização substitutiva de importações, o que lhe permitiu ultrapassar a economia fluminense, que também perderia a localização da capital federal, que se deslocou para Brasília, em 1960.
}

ISSN 1981-9021 - Geo UERJ - Ano 11, v.2, n.19, $1^{\circ}$ semestre de 2009. P. 17-43 www.geouerj.uerj.br/ojs 


\begin{tabular}{|c|c|c|c|c|c|c|c|}
\hline & & \begin{tabular}{|l} 
da \\
populaç \\
ão \\
$(1991-$ \\
$2007)$
\end{tabular} & & & & (2006) & $\begin{array}{l}\% \\
(2006)\end{array}$ \\
\hline Angra dos Reis & 140.345 & $3,50 \%$ & $24,41 \%$ & 275,66 & 328.519 .165 & $66,73 \%$ & 11,3 \\
\hline Cabo Frio & 159.685 & $4,13 \%$ & $24,92 \%$ & 311,03 & $\begin{array}{l}315.439 .716 \\
\left({ }^{*}\right)\end{array}$ & $\begin{array}{l}25,79 \% \\
\left(^{*}\right)\end{array}$ & $45,19\left(^{*}\right)$ \\
\hline $\begin{array}{l}\text { Duque de } \\
\text { Caxias }\end{array}$ & 842.890 & $1,46 \%$ & $26,85 \%$ & 226,14 & 828.456 .536 & $55,40 \%$ & 5,16 \\
\hline Macaé & 156.410 & $3,30 \%$ & $14,17 \%$ & 392,94 & 801.082 .699 & $33,53 \%$ & 54 \\
\hline Nova Friburgo & 177.388 & $0,37 \%$ & $12,88 \%$ & 366,84 & 167.032 .316 & $35,46 \%$ & 0,00 \\
\hline Teresópolis & 148.965 & $1,38 \%$ & $16,56 \%$ & 366,61 & 155.795 .759 & $36,25 \%$ & 5,28 \\
\hline Volta Redonda & 255.695 & $0,93 \%$ & $15,92 \%$ & 348,17 & 362.465 .078 & $48,94 \%$ & 0,00 \\
\hline $\begin{array}{l}\text { Estado do Rio } \\
\text { de Janeiro }\end{array}$ & $\begin{array}{l}15.420 .4 \\
50\end{array}$ & $1,17 \%$ & $19,23 \%$ & 413,94 & $\begin{array}{l}16.906 .856 .83 \\
2\end{array}$ & $47,36 \%$ & \\
\hline
\end{tabular}

Fontes: IBGE: Contagem populacional, 2007; STN: FINBRA, 2006; IBGE: Síntese dos Indicadores Sociais, 2000.

(*) Em 2005.

$\left.{ }^{* *}\right)$ Pessoas que vivem com renda inferior a meio salário mínimo.

$\left.{ }^{* \star *}\right)($ Receita tributária própria + transferências do ICMS) / despesas orçamentárias (\%).

Existem no Estado do Rio de Janeiro 20 municípios com população entre 100 mil e 1 milhão de habitantes; formam o que este estudo denomina cidades médias. Metade dessas cidades está situada dentro da Região Metropolitana do Rio de Janeiro, tendo a ISSN 1981-9021 - Geo UERJ - Ano 11, v.2, n.19, $1^{\circ}$ semestre de 2009. P. 17-43 www.geouerj.uerj.br/ojs 
capital estadual por núcleo. Trata-se, em sua maioria, de municípios que foram surgindo, a partir da década de 1940, como cidades-dormitório de trabalhadores que faziam movimentos pendulares até o município do Rio de Janeiro. Alguns desses municípios, contudo, têm conseguido superar essa condição e passam a apresentar algum grau de centralidade e independência frente à capital estadual. Entre eles encontra-se Duque de Caxias, município que tem apresentado o maior crescimento do PIB e da geração de empregos nesta primeira década do terceiro milênio ${ }^{6}$, o que está relacionado à presença não só da refinaria de petróleo, mas também da indústria química. Duque de Caxias é o primeiro dos sete municípios incluídos nesta pesquisa.

As outras dez cidades médias localizam-se no interior fluminense, de onde foram escolhidas as demais seis cidades objeto deste estudo. O processo de escolha buscou atingir diferentes regiões geoeconômicas, com distintas bases econômicas. Assim, Angra dos Reis foi escolhida pela importância da retomada da indústria naval, associada ao dinamismo de uma das duas principais regiões turísticas do estado. Cabo Frio foi incluída por se localizar na região que tem experimentado o maior crescimento demográfico estadual, associado ao turismo e aos royalties do petróleo. Macaé é a cidade que abriga o núcleo da economia do petróleo, sendo o único município fluminense que vem crescendo sustentadamente desde a década de 1980. Nova Friburgo é uma tradicional e importante cidade média da Região Serrana cuja economia está baseada em um Arranjo Produtivo Local (APL) de moda íntima. Volta Redonda também é uma importante e tradicional cidade média do interior fluminense, devido à presença da Companhia Siderurgia Nacional (CSN), primeira grande siderúrgica brasileira, fundada em 1941 e origem do pólo metal-mecânico existente na região do Médio Paraíba fluminense. Finalmente, Teresópolis, outra tradicional cidade do interior fluminense, também localizada na Região Serrana, foi escolhida por estar experimentando um processo de ocupação extremamente desordenado, com a sede municipal espremida entre dois parques protegidos pela legislação ambiental mas sofrendo forte especulação fundiária.

\footnotetext{
${ }^{6}$ SANTOS e JULIASSE, 2006.

ISSN 1981-9021 - Geo UERJ - Ano 11, v.2, n.19, $1^{\circ}$ semestre de 2009. P. 17-43 www.geouerj.uerj.br/ojs
} 
Como indica a Tabela 1, os maiores municípios em população são Duque de Caxias e Volta Redonda. O primeiro continua a crescer e tem experimentado o fortalecimento de sua economia associada ao beneficiamento do petróleo, mas Volta Redonda tem sofrido ainda os impactos negativos da privatização da CSN, ocorrido no início da década de 1990, o que gerou crise econômica e estabilização demográfica.

Os municípios de Nova Friburgo e Teresópolis também experimentam estagnação demográfica e econômica, mas a renda mais elevada de sua população, combinada com menor percentual de pobres, diminui o potencial de conflito e permite que sua população seja mais identificada com o território. Esse é mais o caso de Nova Friburgo do que de Teresópolis, onde o conflito entre a legislação ambiental e o processo de urbanização tem gerado um enorme passivo ambiental, com muita desordem urbanística.

Macaé é a cidade com a mais forte pressão populacional e econômica, resultado da continuada expansão da extração de petróleo, o que lhe permite proporcionar a seus residentes o mais elevado nível médio de rendimento. Esse valor tem se mantido, em face da fixação da população pobre que migra para a região petrolífera em municípios vizinhos de Macaé, onde o preço da terra é mais baixo. Assim, sua economia tem se fortalecido e os investimentos públicos municipais têm se elevado, alimentados pelo aumento de seu orçamento, não apenas devido ao melhor desempenho da arrecadação própria, mas principalmente pela apropriação das receitas de royalties petrolíferos. Estes, aliás, são o principal componente do orçamento do município de Cabo Frio, um importante balneário da orla estadual e que se localiza próximo a Macaé, de frente para a Bacia de Campos, local de extração de petróleo offshore no Estado do Rio de Janeiro.

O recebimento dessas receitas petrolíferas é um importantíssimo componente da receita de vários municípios fluminenses. Entre os municípios da pesquisa, os principais beneficiários são Macaé e Cabo Frio, o que os leva a apresentar a menor taxa de autonomia financeira municipal (medida pela participação percentual das receitas dependentes do dinamismo econômico local em relação ao valor das suas despesas 
orçamentárias). Na verdade, a entrada dessas receitas, em percentuais que chegam a representar $50 \%$ das receitas orçamentárias dos dois municípios, torna-os mais prósperos, mas essa prosperidade depende da sustentação da extração de petróleo, o que se reflete na atração de novos fluxos migratórios.

As receitas petrolíferas também fazem parte das receitas municipais de Angra dos Reis, Duque de Caxias e Teresópolis, mas apresentam menor peso. Os outros dois municípios (Nova Friburgo e Volta Redonda) não têm esse tipo de receita; portanto, não participam do rateio dessa nova fonte de recursos que tem permitido maior folga financeira aos governos locais. Ainda assim, apresentam elevado grau de autonomia financeira, correspondente a valores entre $35 \%$ e $50 \%$ de suas despesas orçamentárias.

Os municípios selecionados são, portanto, atores com potencial de experimentar a descentralização das políticas públicas como uma inovação do processo de reforma do Estado. Seus portes demográfico e econômico os tornam capazes técnica e financeiramente de formular e financiar algumas políticas locais. Contudo, tais políticas serão mais bem executadas quanto maior for o controle sobre o poder público, segundo uma das premissas sobre as quais está assentada a defesa da descentralização do Estado. Esta é a tarefa a que este estudo se propõe: verificar, na prática, como vêm sendo realizados os controles exercidos pelo Tribunal de Contas do Estado; o controle social e o realizado pelo Ministério Público Estadual.

\section{4 - O controle externo sobre a gestão municipal}

Nesta seção, analisam-se os dados da pesquisa de campo. Na primeira subseção, são resumidos os resultados do controle social e na segunda seção analisa de forma mais detalhada os dados relativos ao controle exercido pelo Ministério Público do Estado do Rio de Janeiro.

\section{1- Controle social: o funcionamento dos conselhos municipais}


O Brasil experimentou um processo de redemocratização das estruturas de poder depois de 21 anos de ditadura militar, que culminou com a entrada em vigor da Constituição de 1988. Esta, que foi denominada "Constituição Cidadã", introduziu novos direitos sociais e difusos, bem como criou instrumentos que garantissem a efetividade dos direitos dos cidadãos. Entre entes, destacam-se os conselhos municipais de saúde e educação, visando controlar a execução de políticas que foram descentralizadas e passaram a ser responsabilidade dos governos municipais.

A pesquisa de campo abrangeu uma investigação sobre o funcionamento destes conselhos municipais, além do conselho de política urbana, uma política de competência municipal. Ao longo do período entre os anos de 2000 a 2005, buscamos verificar como se constituíram tais conselhos; com que periodicidade seus membros se reuniam; como se elegiam seus presidentes; de onde se originavam as informações analisadas pelos conselheiros, bem como a possível descoberta de irregularidades e os desdobramentos que elas acarretariam. $O$ acesso às atas das reuniões dos conselhos foi o instrumento principal da pesquisa, que também incluiu entrevistas com conselheiros.

O resultado encontrado aponta para uma grande ineficácia do controle exercido pelos conselhos, ainda que tenham sido formalmente criados e funcionem de modo como está estabelecido na legislação federal que os criou.

Antes de discutir os resultados do funcionamento dos conselhos de saúde e educação, é preciso tecer comentários sobre os conselhos de política urbana. A pesquisa descobriu que no caso destes conselhos, nem a sua criação formal está resolvida. Por ser uma política de competência municipal - e sua organização depender do que dispuser o Plano Diretor-, grande parte dos conselhos ainda nem foi criada. A razão disso está no longo período que decorreu entre a previsão de que os municípios elaborem seus planos diretores (em 1988) e a entrada em vigor da lei federal que estabeleceu as diretrizes gerais de política urbana, a chamada lei do Estatuto das Cidades (em 2001). Segundo esta lei, os municípios deveriam elaborar e/ou atualizar seus planos diretores, considerados os instrumentos de política urbana, até 5 anos ISSN 1981-9021 - Geo UERJ - Ano 11, v.2, n.19, $1^{\circ}$ semestre de 2009. P. 17-43 www.geouerj.uerj.br/ojs 
depois da entrada em vigor da lei. Assim, esperava-se que em 2006 todos os municípios da pesquisa já contassem com o seu plano diretor, o que não ocorreu. Passou a prevalecer a tese jurídica segundo a qual o executivo municipal deveria ter enviado ao poder legislativo sua proposta de lei, mas que não poderia obrigá-lo a votar e, eventualmente, aprovar a lei no prazo previsto (outubro de 2006). Assim, a pesquisa referente ao funcionamento dos conselhos de política urbana foi totalmente prejudicada, o que já é um elemento que aponta para a desconsideração da importância da política urbana.

Quanto ao funcionamento dos conselhos de saúde e educação, verificamos que apesar da sua constituição em todos os municípios, em apenas 3 foi possível levantar as informações necessárias sobre o conselho de educação. Em alguns municípios nem foi possível descobrir onde os conselheiros se reuniam, se haveria uma sede própria para abrigar os trabalhos dos conselheiros. A pesquisa sobre o controle social somente conseguiu apurar informações segundo uma mesma metodologia no caso dos conselhos de saúde. E, mesmo neste caso, não foi possível reunir as informações relativas a um dos municípios (Angra dos Reis). Os dois quadros abaixo resumem as principais informações coletadas.

Conselhos Municipais de Saúde

\begin{tabular}{|c|c|c|}
\hline Município & $\begin{array}{l}\text { Forma de escolha do presidente do } \\
\text { Conselho }\end{array}$ & $\begin{array}{l}\text { Origem do presidente } \\
\text { atual }\end{array}$ \\
\hline Cabo Frio & $\begin{array}{l}\text { Determinada por lei }- \text { secretário } \\
\text { Municipal de Saúde }\end{array}$ & $\begin{array}{l}\text { Secretário Municipal de } \\
\text { Saúde }\end{array}$ \\
\hline $\begin{array}{l}\text { Duque } \\
\text { Caxias }\end{array}$ & Informação não disponibilizada & $\begin{array}{l}\text { Informação não } \\
\text { disponibilizada }\end{array}$ \\
\hline Macaé & Determinada por lei & $\begin{array}{l}\text { Secretário Municipal de } \\
\text { Saúde }\end{array}$ \\
\hline
\end{tabular}

ISSN 1981-9021 - Geo UERJ - Ano 11, v.2, n.19, $1^{\circ}$ semestre de 2009. P. 17-43 www.geouerj.uerj.br/ojs 


\begin{tabular}{|c|c|c|}
\hline $\begin{array}{l}\text { Nova } \\
\text { Friburgo }\end{array}$ & $\begin{array}{l}\text { Determinada por lei }- \text { Secretário } \\
\text { Municipal de Saúde }\end{array}$ & $\begin{array}{l}\text { Secretário Municipal de } \\
\text { Saúde }\end{array}$ \\
\hline Teresópolis & Informação não disponibilizada & $\begin{array}{l}\text { Informação não } \\
\text { disponibilizada }\end{array}$ \\
\hline $\begin{array}{l}\text { Volta } \\
\text { Redonda }\end{array}$ & Eleição & Segmento dos usuários \\
\hline
\end{tabular}

Fonte: Pesquisa de campo.

\begin{tabular}{|c|c|c|c|c|}
\hline Município & $\begin{array}{l}\text { Periodicidade } \\
\text { das reuniões }\end{array}$ & $\begin{array}{l}\text { Informações/questões } \\
\text { debatidas }\end{array}$ & $\begin{array}{l}\text { Origem das } \\
\text { informações/questões } \\
\text { debatidas }\end{array}$ & $\begin{array}{l}\text { Irregularidades } \\
\text { constatadas pelo } \\
\text { Conselho Municipal } \\
\text { de Saúde }\end{array}$ \\
\hline Cabo Frio & Mensal & $\begin{array}{l}\text { Programas de saúde; } \\
\text { aprovação de contas }\end{array}$ & $\begin{array}{l}\text { Secretário Municipal de } \\
\text { Saúde }\end{array}$ & Nenhuma \\
\hline $\begin{array}{l}\text { Duque de } \\
\text { Caxias }\end{array}$ & Mensal & Programas de saúde & Conselheiros & $\begin{array}{l}\text { Má aplicação de } \\
\text { verbas }\end{array}$ \\
\hline Macaé & Mensal & Aprovação de contas & $\begin{array}{l}\text { Secretaria Municipal de } \\
\text { Saúde }\end{array}$ & Nenhuma \\
\hline $\begin{array}{l}\text { Nova } \\
\text { Friburgo }\end{array}$ & Mensal & $\begin{array}{l}\text { Programas de saúde; } \\
\text { aprovação de contas }\end{array}$ & $\begin{array}{l}\text { Fundação Municipal de } \\
\text { Saúde }\end{array}$ & Nenhuma \\
\hline Teresópolis & Mensal & Programas de saúde & $\begin{array}{l}\text { Conselheiros; } \\
\text { Defensoria }\end{array}$ & $\begin{array}{l}\text { Falta de medicação; } \\
\text { demora no } \\
\text { atendimento do setor } \\
\text { ortopédico do } \\
\text { Hospital das Clínicas }\end{array}$ \\
\hline $\begin{array}{l}\text { Volta } \\
\text { Redonda }\end{array}$ & Mensal & $\begin{array}{l}\text { Programas de saúde; } \\
\text { aprovação de contas }\end{array}$ & $\begin{array}{l}\text { Secretaria Municipal de } \\
\text { Saúde }\end{array}$ & Nenhuma \\
\hline
\end{tabular}

Fonte: Pesquisa de campo.

ISSN 1981-9021 - Geo UERJ - Ano 11, v.2, n.19, $1^{\circ}$ semestre de 2009. P. 17-43

www.geouerj.uerj.br/ojs 
Conforme já mencionado, os dados sugerem que os conselhos de saúde estão em funcionamento e se organizam basicamente conforme o que está estabelecido na lei que os criou. Ainda que ocorram algumas diferenças entre um município e outro, podemos verificar que são dominados por conselheiros oriundos do poder executivo, os quais definem as informações a serem disponibilizadas, o que não pode deixar de refletir o domínio dos gestores públicos sobre os demais membros dos conselhos.

Este resultado aponta para um parcial fracasso dos conselhos municipais. Eles não garantem a efetividade dos direitos dos cidadãos, uma vez que são capturados pelos governos locais através da ação de conselheiros que são membros do poder executivo municipal. Ainda assim, constituem um espaço que pode vir a ser ocupado por redes sociais mais preocupadas com as condições de funcionamento da política pública do que com a sustentação da administração de plantão. Ao serem realizados estudos em que se evidencia o fraco desempenho destes conselhos, ocorre, simultaneamente, maior compreensão sobre a importância de serem desenvolvidas outras estratégias de controle social, como, por exemplo, a elaboração de indicadores que possam servir de instrumentos de avaliação da execução das políticas.

No entanto, o que parece ainda prevalecer é a situação descrita por José Murilo de Carvalho (2001), segundo a qual o brasileiro experimenta a "estadania", ao invés de "cidadania", na sua relação com o Estado. Analisando a história brasileira da perspectiva dos avanços e recuos dos direitos dos cidadãos, este historiador verificou que os direitos sociais no Brasil não foram conquistados após a disseminação dos direitos civis e políticos. Ao contrário, avançaram durante regimes ditatoriais (1930-45 e 1964-1985), tendo sido entendidos como concessão do Estado autoritário para se legitimar socialmente.

Ao ser promulgada a Constituição de 1988, houve muitos avanços nos direitos sociais e difusos, mas também muito ceticismo a respeito da viabilidade de efetivar os direitos ali previstos. O custo da provisão daqueles direitos foi considerado causa da crise de governabilidade e um dos responsáveis pela crise inflacionária ao criar expectativas difíceis de serem cumpridas (SANTOS, 2006a).

ISSN 1981-9021 - Geo UERJ - Ano 11, v.2, n.19, $1^{\circ}$ semestre de 2009. P. 17-43 www.geouerj.uerj.br/ojs 
Neste contexto, consideramos que a cultura política no Brasil é ainda muito autoritária, com o Estado ainda se sobrepondo à sociedade civil, o que resulta num fraco controle social das políticas públicas por meio de conselhos municipais. A sociedade acredita mais no potencial do controle exercido pelo Ministério Público e transfere para essa instituição a enorme responsabilidade para assegurar parte dos direitos sociais e difusos criados com a redemocratização do Estado brasileiro a partir de 1985.

\section{2 - O controle exercido pelo Ministério Público}

O Ministério Público é um órgão que desfruta de grande credibilidade entre as instituições públicas brasileiras. Tal credibilidade foi muito fortalecida pela forte autonomia conquistada desde a Constituição de $1988^{7}$, elaborada no bojo do processo de redemocratização brasileiro. Esse novo marco legal conferiu autonomia para a instituição e independência de atuação para seus membros em graus nunca vistos sob as constituições brasileiras anteriores. Desde então, o Ministério Público tem exercido inúmeras atribuições em defesa da sociedade, mesmo que para isso tenha que contrariar os interesses de autoridades públicas.

O Ministério Público (que existe nos planos federal e estadual) é um órgão constitucional permanente, essencial à função jurisdicional do Estado, incumbindo a ele a defesa da ordem jurídica (pois que ele é o fiscal da execução das leis e da obediência à Constituição); do regime democrático, dos interesses sociais e dos

\footnotetext{
${ }^{7}$ Neste particular, cabe citar o jurista José Afonso da Silva, a propósito do tratamento dispensado ao órgão na história constitucional do País: "a Constituição de 1891 não o mencionou, senão para dizer que um dos membros do Supremo Tribunal Federal seria designado Procurador-Geral da República, mas a Lei 1.030, de 1890, já o organizava como instituição. A Constituição de 1934 o considerou como órgão de cooperação nas atividades governamentais. A de 1946 reservou-lhe um título autônomo, enquanto a de 1967 o incluiu numa seção do capítulo do Poder Judiciário e a sua Emenda 1/69 o situou entre os órgãos do Poder Executivo. Agora, a Constituição lhe dá o relevo de instituição permanente, essencial à função jurisdicional do Estado, incumbindo-lhe a defesa da ordem jurídica, do regime democrático e dos interesses sociais e individuais indisponíveis. DA SILVA, José Afonso. Curso de Direito Constitucional Positivo. 27 ed. São Paulo: Malheiros Editores, 2006, p. 598.
}

ISSN 1981-9021 - Geo UERJ - Ano 11, v.2, n.19, $1^{\circ}$ semestre de 2009. P. 17-43 www.geouerj.uerj.br/ojs 
interesses indisponíveis, referentes, por exemplo, aos direitos assegurados na Constituição, sejam eles individuais e/ou sociais, como o direito à vida, à liberdade, à educação e à saúde, sejam eles difusos, como os relativos ao patrimônio público, ao meio ambiente e ao patrimônio cultural.

Os membros do MP detêm independência funcional para agir sem qualquer tipo de influência externa. Isto é, eles só se sujeitam ao controle de órgãos superiores e diretivos da instituição, mesmo assim somente na sua conduta administrativa ao longo da carreira ou nos seus atos pessoais que afrontem a probidade e os demais deveres legais e constitucionais aos quais estão vinculados. De resto, os membros do Ministério Público atuam com total liberdade funcional e não estão sujeitos a qualquer subordinação hierárquica ou supervisão de qualquer dos órgãos estatais. Essa independência funcional no exercício das funções do MP, por sua vez, é assegurada por um sistema de garantias, vedações e prerrogativas para seus membros, similar ao estabelecido para garantir a independência funcional de juízes ${ }^{8}$.

Para a defesa dos interesses e direitos que lhe cabe promover, o Ministério Público pode tomar inúmeras providências, que importam em controle externo das entidades da Administração Pública direta, indireta e de outros entes privados que prestam serviços públicos ou de relevância pública. Sempre que o membro do MP

\footnotetext{
${ }^{8}$ Os membros do Ministério Público, como agentes políticos, estão investidos de garantias necessárias ao pleno exercício de suas funções. São elas: vitaliciedade, irredutibilidade de subsídio (art. 39, §4 CRFB/88) e inamovibilidade (art. 128, $\S 5^{\circ}$, inc.I CRFB/88). Cabe ainda mencionar que "também se lhe preordenaram garantias de imparcialidade na forma de vedações (art. 128, $\S 5^{\circ}$, II): de receber, a qualquer título ou pretexto, auxílios ou contribuições de pessoas físicas, entidades públicas ou privadas, ressalvadas as exceções previstas em lei; de exercer, ainda que em disponibilidade, qualquer outra função pública, salvo uma de magistério; de exercer atividade político-partidária - essa, agora, é uma proibição absoluta, porque a EC-45/2004 eliminou a possibilidade de a lei estabelecer exceções a ela, com o que ficaram revogados os dispositivos de lei que as tenham e se tornará inconstitucional a que vier a fazê-lo, repercutindo-se também na disposição transitória (ADCT, art. 29, $\S 3^{\circ}$ ); de exercer a advocacia no âmbito jurisdicional em que desempenhava suas atribuições, antes de decorridos três anos do afastamento do cargo por aposentadoria ou exoneração (parece que, com esse enunciado, se atende à determinação de que aos membros do Ministério Público se aplica o disposto no inciso $\mathrm{V}$ do parágrafo único do art. 95, inserido pela mesma EC-45/2004)". DA SILVA, José Afonso. Curso de Direito Constitucional Positivo. 27 ed. São Paulo: Malheiros Editores, 2006, p. 602.
}

ISSN 1981-9021 - Geo UERJ - Ano 11, v.2, n.19, $1^{\circ}$ semestre de 2009. P. 17-43 www.geouerj.uerj.br/ojs 
tiver notícia de qualquer ilegalidade ou abuso praticado por tais entidades ou por cidadãos, mas em prejuízo dos interesses sociais, deve a princípio instaurar procedimento administrativo para apurar o fato, tendo poderes de fazer requisições, expedir notificações e intimações, com vistas a instruir o feito. A falta injustificada e o retardamento indevido do cumprimento das requisições do MP implicarão a responsabilidade de quem Ihe der causa.

Na tentativa de promover a correção da ilegalidade sem a provocação do Poder Judiciário, o MP poderá expedir recomendações visando à cessação das ilegalidades e à correção das condutas, fixando prazo razoável para a adoção das providências cabíveis. Além disso, o Ministério Público poderá promover o ajustamento da conduta de tais entidades à lei e à Constituição, mediante a assinatura de um termo/acordo com combinações específicas, o qual tem eficácia de título executivo extrajudicial.

O Ministério Público tem atuação importante junto às demais formas de controle externo da Administração Pública. Assim, por exemplo, quando não consegue fazer com que entidades públicas, privadas ou até mesmo pessoas deixem de cometer ilegalidades, deve promover junto ao Poder Judiciário ações civis públicas para a defesa de interesses difusos e coletivos, dentre os quais incluem-se a defesa da ordem urbanística e do meio ambiente, além dos direitos à saúde e educação.

Neste estudo, investigamos a ação do Ministério Público junto ao poder público dos municípios selecionados, focalizando o período de 2000 a 2005, justamente no que tange aos direitos difusos e coletivos mencionados. Os instrumentos da atuação do órgão foram divididas entre procedimentos investigatórios $(\mathrm{PI})$, ações civis públicas $(A C P)$ e termos de ajustamento de conduta (TAC).

O inquérito civil é o instrumento de investigação de atribuição exclusiva do Ministério Público para apuração de atos violadores dos direitos também chamados transindividuais. É iniciado por uma portaria, devidamente numerada e assinada pelo Promotor de Justiça que o preside, contendo as diligências a serem efetivadas durante a investigação e as peças até então colhidas. 
Ao final do inquérito civil, apurada a inexistência do dano ou ilícito ou verificado o esgotamento dos meios investigatórios sem que se lograsse êxito em provar a lesão, procede-se ao arquivamento do procedimento, em promoção justificada, que é submetida a homologação pelo Conselho Superior do Ministério Público.

Por outro lado, se o dano restar comprovado, podem ser trilhados dois caminhos: o ajuizamento de ação civil pública ou a propositura de termo de ajustamento de conduta.

O termo de ajustamento de conduta (TAC) é um dos instrumentos mais eficazes para a reparação dos danos causados aos direitos difusos, coletivos e individuais homogêneos. Pode ser proposto tanto pelo Ministério Público quanto pelo investigado, e consiste num instrumento através do qual o causador do dano se compromete a adequar sua conduta, de forma a cessar a lesão e ao mesmo tempo repará-la. O TAC deve possuir um conteúdo mínimo, com a determinação específica das providências a serem adotadas, do cronograma (prazo mínimo e máximo para a execução das medidas) e das multas a serem aplicadas na hipótese de descumprimento.

A pesquisa buscava elaborar um quadro-síntese com o número de intervenções do Ministério Público, segundo fossem: a) procedimentos investigatórios (PI); b) ações civis públicas (ACP); ou ainda $\mathrm{c}$ ) termos de ajustamento de conduta (TAC). Além disso, cada um desses instrumentos seria considerado em relação às diferentes políticas: a) ordenamento urbanístico; b) defesa do meio ambiente (em apenas dois casos foi possível separar o meio ambiente natural do meio ambiente construído); c) do acesso à saúde; e d) do acesso à educação. Essas são as principais políticas sob a responsabilidade dos municípios; a primeira é de competência da esfera municipal, enquanto as demais são compartilhadas entre as três esferas de governo, mas que foram objeto de descentralização, prevendo-se sua execução nos municípios.

No município de Macaé, a tarefa mostrou-se impossível, impedindo que fosse elaborado o quadro-síntese da atuação do Ministério Público. Em outro caso, no município de Volta Redonda, o órgão mostrou grande receptividade, mas elaborou um 
quadro próprio ${ }^{9}$, distinto daquele elaborado durante a fase dos procedimentos metodológicos da pesquisa. Nessas condições, o quadro apresentado a seguir referese à soma do número de procedimentos em cada caso para apenas cinco dentre os sete municípios selecionados no estudo.

Tabela 2: Número de intervenções do Ministério Público segundo o instrumento utilizado em cada política considerada, durante o período 2000 a 2005, nos municípios de Angra dos Reis, Cabo Frio, Duque de Caxias, Nova Friburgo e Teresópolis.

\begin{tabular}{|c|c|c|c|c|c|c|c|}
\hline \multicolumn{2}{|c|}{ ANO } & \multirow{2}{*}{$\begin{array}{l}2000 \\
2\end{array}$} & \multirow[b]{2}{*}{$\begin{array}{l}2001 \\
1 \\
14 \\
1\end{array}$} & \multirow{2}{*}{$\begin{array}{l}2002 \\
4 \\
4\end{array}$} & \multirow{2}{*}{$\begin{array}{l}2003 \\
13\end{array}$} & \multirow[b]{2}{*}{$\begin{array}{l}2004 \\
2 \\
31 \\
7\end{array}$} & \multirow{2}{*}{$\begin{array}{l}2005 \\
3 \\
15 \\
1\end{array}$} \\
\hline C & $\begin{array}{l}\text { Ordenamento } \\
\text { urbanístico } \\
\text { Meio ambiente } \\
\text { Saúde } \\
\text { Educação }\end{array}$ & & & & & & \\
\hline $\mathbf{P}$ & $\begin{array}{l}\text { Ordenamento } \\
\text { urbanístico } \\
\text { Meio ambiente } \\
\text { Saúde } \\
\text { Educação }\end{array}$ & 6 & $\mid \begin{array}{l}8 \\
1\end{array}$ & $\begin{array}{l}8 \\
3\end{array}$ & 13 & $\mid \begin{array}{l}18 \\
8 \\
4\end{array}$ & $\left\{\begin{array}{l}15 \\
6 \\
1\end{array}\right.$ \\
\hline & Ordenamento & 6 & 10 & 35 & 27 & 34 & 30 \\
\hline
\end{tabular}

${ }^{9} \mathrm{O}$ quadro elaborado pelo Ministério Público de Volta Redonda é o seguinte:

\begin{tabular}{|l|l|l|l|l|l|l|l|l|l|}
\hline \multicolumn{2}{|c|}{ ANO } & 1999 & 2000 & 2001 & 2002 & 2003 & 2004 & 2005 & 2006 \\
\hline \multirow{3}{*}{ IC } & Cidadania & 6 & 0 & 3 & 6 & 19 & 21 & 40 & 29 \\
\cline { 2 - 10 } & Meio ambiente & 1 & 0 & 4 & 2 & 8 & 14 & 16 & 16 \\
\hline \multirow{3}{*}{ PP } & Cidadania & 0 & 0 & 0 & 0 & 5 & 0 & 6 & 9 \\
\cline { 2 - 10 } & Meio ambiente & 0 & 0 & 0 & 0 & 3 & 3 & 4 & 4 \\
\hline \multirow{3}{*}{ Total } & Cidadania & 6 & 0 & 3 & 6 & 24 & 21 & 46 & 38 \\
\cline { 2 - 10 } & Meio ambiente & 1 & 0 & 4 & 2 & 11 & 17 & 20 & 20 \\
\cline { 2 - 10 } & Total & 7 & 0 & 7 & 8 & 35 & 38 & 66 & 58 \\
\hline
\end{tabular}




\begin{tabular}{l|l|l|l|l|l|l|l} 
Prbanístico & $\begin{array}{l}\text { Meio ambiente } \\
\text { I }\end{array}$ & 38 & 59 & 223 & 212 & 191 & 264 \\
Saúde & 6 & 7 & 15 & 22 & 29 & 56 \\
Educação & & & 5 & 9 & 12 & 13 \\
\hline \hline
\end{tabular}

Fonte: Elaboração própria, a partir de dados coletados nas Promotorias de Justiça dos municípios.

A atuação do Ministério Público tem se intensificado ao longo do período considerado, o que sugere a consolidação do papel da instituição na defesa dos interesses difusos e coletivos. Como já era de se esperar, o número de procedimentos investigatórios foi o mais expressivo, com destaque para a defesa do meio ambiente. A política urbana, que é de competência exclusiva do município, responsável pelo ordenamento urbanístico, não mereceu a mesma defesa, que envolveu inclusive um número menor de procedimentos investigatórios do que as políticas descentralizadas de acesso à saúde e educação.

Dentre os dois instrumentos de intervenção depois que o Ministério Público avança nos procedimentos investigatórios, as ações civis públicas foram um pouco mais freqüentes que os termos de ajustamento de conduta. Aquelas, no entanto, envolvem tramitação longa, mediante o sistema judiciário, o que, além de não garantir a defesa dos direitos, contribui para diminuir a efetividade dos direitos difusos e coletivos. Os TACs, ao contrário, tendem a produzir resultados em menor tempo, o que conduz à maior efetividade dos direitos.

Cabe destacar que a defesa do meio ambiente é a política que domina os termos de ajustamento de conduta: dos 82 TACs, 67 foram referentes ao meio ambiente. Esse resultado sugere que essa é a política que tem merecido maior efetividade em sua defesa. Portanto, mais do que a ordem urbanística e os direitos sociais à saúde e educação, o meio ambiente tem contado com maior apoio institucional em sua defesa, não obstante a importância dos demais setores das políticas públicas. 
Resta acrescentar que o conjunto das informações dos municípios selecionados escamoteia uma evidência que merece ser destacada. Trata-se do maior ativismo da Promotoria de Justiça nos municípios de Nova Friburgo e de Volta Redonda. Esses dois são justamente os municípios com menores taxas de crescimento demográfico e dinamismo econômico. Possivelmente tal estabilidade contribua para que sua população tenha maior identificação com o território e que isso se expresse por maior pressão pela efetividade dos seus direitos de cidadania. Isso é especialmente destacado no caso de Volta Redonda, que foi o único município onde o Ministério Público atuou mais intensamente em ações que defendem os direitos de cidadania (saúde e educação) do que na defesa do meio ambiente.

A facilidade na solução de conflitos de ordem ambiental se deve tanto à boa estrutura do Ministério Público nesse setor quanto aos instrumentos legais de que se pode dispor. Nos quadros do Ministério Público, existem inúmeros peritos que integram o denominado GATE (Grupo de Apoio Técnico Especializado), formado por equipe multidisciplinar da qual constam biólogos, químicos, arquitetos, engenheiros das mais diversas especialidades (florestais, sanitaristas, químicos, cartógrafos, de trânsito e de orçamento, dentre outros). Tais especialistas não raro emitem parecer técnico auxiliando a atuação ministerial.

Ademais, a legislação ambiental é bastante objetiva no tocante às normas técnicas, à reparação do dano ambiental, às penalidades aplicáveis aos responsáveis, facilitando o trabalho do Promotor de Justiça. Os instrumentos processuais do inquérito civil, do termo de ajustamento de conduta e da ação civil pública podem, assim, ser utilizados com uma eficácia bem maior.

O mesmo não ocorre, lamentavelmente, quando se trata de políticas de saúde e educação. A legislação, embora bastante elogiável em seus valores e disposições, não tem sido eficaz porque os réus dos ilícitos cometidos são geralmente representantes do Poder Executivo local. No sistema político vigente no Brasil, as prefeituras conseguem minimizar os efeitos dos controles institucionais a que estão sujeitas por meio de parcerias com interesses políticos regionais (governos estaduais). Quanto maior for o 
peso político de uma prefeitura, tanto maior a chance de que consiga escapar dos efeitos da legislação através de inúmeros procedimentos, dentro os quais destaca-se a alegação de "crise de governabilidade".

Regras que obrigam à aplicação de percentuais orçamentários são ignoradas por mecanismos criados pela própria lei orçamentária, que permite alguns reajustes na destinação de verbas, além de despesas não propriamente identificadas, que muitas vezes se destinam à propaganda do governo, por exemplo. Na tentativa de buscar o cumprimento da lei, o Ministério Público exige, recomenda e finda por intentar demanda judicial, porém esbarra com a constante alegação do poder público de que lhe falta verba para a execução das políticas (sustentada no denominado “princípio da reserva do possível"). O Poder Judiciário, por sua vez, não raro acata tal afirmação e, de forma conservadora e acomodada, decide não se imiscuir em tais matérias, as quais estariam protegidas pelo mérito do administrador público em optar pela política que melhor lhe aprouver. E assim vão ocorrendo, sucessivamente, várias atitudes desrespeitosas com os direitos dos cidadãos.

Por fim, como justificativa ainda para a atuação do Ministério Público abaixo das elevadas expectativas nas questões relativas às políticas públicas, tem-se o crescente número de casos envolvendo atos de improbidade administrativa. Trata-se de casos de desvio de recursos, de esquemas de corrupção, de concursos fraudados, de licitações superfaturadas e outros tantos são cada vez mais numerosos, absorvendo a maior parte da demanda do Ministério Público. Tais procedimentos acabam por absorver toda a atuação ministerial da região; os Promotores de Justiça são obrigados, muitas vezes, a mobilizar menos esforços no que tange às demais matérias.

\section{5 - Conclusões}

A conclusão geral do estudo aponta para um quadro em que os controles sobre os governos municipais precisam avançar, estando ainda distantes daquilo que a teoria institucionalista sustenta como necessário para dar suporte à melhoria nas políticas ISSN 1981-9021 - Geo UERJ - Ano 11, v.2, n.19, $1^{\circ}$ semestre de 2009. P. 17-43 www.geouerj.uerj.br/ojs 
descentralizadas. É preciso reconhecer, todavia, que vem ocorrendo uma mudança cultural que pode conduzir à maior responsabilização do gestor público, com maior envolvimento da população no processo de desenvolvimento local.

Este estudo permite avançar em outras conclusões parciais:

1. o Ministério Público é mais ativo na defesa ambiental do que na ordem urbanística;

2. os municípios submetidos às maiores pressões demográficas e econômicas são aqueles em que a efetividade dos controles é menor (casos de Macaé e Cabo Frio);

3. nos municípios com maior estabilidade demográfica e econômica, ocorre maior controle sobre a cidadania, definida como os direitos à saúde e à educação (casos de Nova Friburgo e Volta Redonda);

4. o controle social está institucionalizado, mas carece de efetividade no que tange às políticas descentralizadas de saúde e educação;

5. o controle social sobre a ordem urbanística é o mais frágil dentre os direitos difusos e coletivos.

Este resultado sugere que a política urbana, justamente aquela de competência dos governos municipais, é a que menos está submetida ao controle externo. $\mathrm{O}$ atraso na mera institucionalização dos conselhos de política urbana é um indicador da pouca mobilização da sociedade para ordenar o espaço urbano, o que se coaduna com a insuficiente atuação do Ministério Público na defesa da ordem urbanística. Ainda não há a clareza necessária sobre a natureza coletiva da cidade, um direito difuso que deve ser protegido em benefício da sociedade, como é o objetivo da política urbana expresso na Constituição da República.

Acrescente-se, ainda, que a descentralização das políticas públicas em favor dos Municípios pode ser um instrumento associado à maior democratização das estruturas de poder, mas não é suficiente para garanti-la. Além disso, não se deve alimentar a expectativa de que a ação do Ministério Público possa substituir a participação social no que tange ao controle externo sobre os governos municipais, sobretudo em relação à ISSN 1981-9021 - Geo UERJ - Ano 11, v.2, n.19, $1^{\circ}$ semestre de 2009. P. 17-43 www.geouerj.uerj.br/ojs 
política urbana. Ainda assim, a insuficiente ação do Ministério Público conjugada a dos conselhos municipais contribuem para disseminar e fortalecer outros mecanismos de controle social, como, por exemplo, a elaboração de indicadores para acompanhamento da execução das políticas públicas.

\section{6 - Referências bibliográficas}

ABRUCIO, F. e LOUREIRO, M. R. Finanças Públicas, democracia e accountability. In: BIDERMAN, C. e ARVATE, P. (Orgs.). Economia do setor público no Brasil. Rio de Janeiro: Elsevier, 2004.

BARROS, A. M. Controlando as políticas públicas: o papel dos conselhos municipais. In: UERJ/Faculdade de Direito. Revista do Direito da Cidade. n. 4, 2008.

CARVALHO, J. Murilo. Cidadania no Brasil. O longo caminho. Rio de Janeiro: Civilização Brasileira, 2001

CAVALCANTI, R. N. O papel do Ministério Público no controle externo da gestão municipal e das políticas públicas. In: UERJ/Faculdade de Direito. Revista do Direito da Cidade, n. 4, 2008.

DAHL, R. A. Sobre a democracia. Brasília: Editora UnB, 2001.

DA SILVA, José Afonso. Curso de Direito Constitucional Positivo. 27 ed. São Paulo: Malheiros Editores, 2006.

IBGE. Indicadores sociais municipais, 2000.

NORTH, Douglas. Institutions, institutional change and economic performance. Cambridge: Cambridge University Press, 1990.

PUTNAM, R. D. Comunidade e democracia: a experiência da Itália moderna. Rio de Janeiro: FGV, 1998.

RESENDE, F. (Coord.). Desafios do federalismo fiscal. Rio de Janeiro: FGV, 2006.

ISSN 1981-9021 - Geo UERJ - Ano 11, v.2, n.19, $1^{\circ}$ semestre de 2009. P. 17-43

www.geouerj.uerj.br/ojs 
RESTREPO, D. e CÁRDENAS, R. Descentralización, desarrollo y integración: crises del centralismo y nuevos retos para las entidades territoriales. Anais do VIII Encontro do Seminário Internacional da Rede Iberoamericana de Investigadores de Globalização e Território. Rio de Janeiro, maio de 2004.

RESTREPO, D. (Org). Histórias de descentralización, transformación del régimen político y cambio en el modelo de desarrollo en América Latina, Europa y EUA. Bogotá: Universidad Nacional de Colômbia, 2006.

SANTOS, A. M. S. P. Municípios como atores de políticas públicas: descentralização, controle externo e gestão municipal. In: UERJ/Faculdade de Direito. Revista do Direito da Cidade, n. 4, 2008.

SANTOS, A. M. S. P. Hitos, componentes y resultados de la descentralización en Brasil. In: RESTREPO, D. Historias de descentralización, transformación del régimen político y cambio en el modelo de desarrollo en América Latina, Europa y EUA. Bogotá: Universidad Nacional de Colômbia, 2006a.

SANTOS, A M. S. P. Federalismo no Brasil: da autonomia à cooperação. In: PAULA, L. F., FERREIRA, L. R. e ASSIS, M. (Orgs.). Perspectivas para a economia brasileira. Inserção internacional e políticas públicas. Rio de Janeiro: Eduerj, 2006b.

SANTOS, A. M. S. P. e JULIASSE, W. T. Redistribuição espacial: o papel das cidades médias brasileiras. Anais do XI Encontro Nacional de Economia Política. Vitória, 13 a 16 de junho de 2006.

SANTOS, A. M. S. P. e UGÁ, M. A. D. Reformas do Estado, descentralização e políticas de saúde: uma análise comparada entre Argentina, Brasil, Colômbia e México. In: Secretaria de Planejamento e Gestão. Fundação de Economia e Estatística Siegfried Emanuel Heuser: Revista Ensaios FEE, vol. 28, n. 2, 2007.

WORLD BANK. Relatório sobre o Desenvolvimento Mundial 1997. O Estado num mundo em transformação.

WORLD BANK. Relatório do Desenvolvimento Humano 2002. Aprofundar a democracia num mundo fragmentado. Queluz: Mensagem, 2003.

ISSN 1981-9021 - Geo UERJ - Ano 11, v.2, n.19, $1^{\circ}$ semestre de 2009. P. 17-43

www.geouerj.uerj.br/ojs 
Artigo encaminhado para publicação em maio de 2009.

Artigo aceito para publicação em julho de 2009.

ISSN 1981-9021 - Geo UERJ - Ano 11, v.2, n.19, $1^{\circ}$ semestre de 2009. P. 17-43 www.geouerj.uerj.br/ojs 